\title{
Correlation between Genotoxicity and Interleukin-6 in Smokers: A Rodent Model
}

\author{
Aneela Jamil1, Amir Rashid² and Asifa Majeed²
}

\begin{abstract}
Objective: To investigate the relation between genotoxicity and interleukin-6 in rats exposed to cigarette smoke.

Study Design: An experimental study.

Place and Duration of Study: Army Medical College, Rawalpindi and Armed Forces Institute of Pathology, Rawalpindi, in 2016.

Methodology: Seventy healthy Sprague Dawley rats were placed in smoke chambers at animal house of National Institute of Health, Islamabad. Cigarette smoke was given to them for 3 months. Genotoxicity was assessed by Cytokinesis Block Micronucleus (CBMN) assay. Enzyme linked immunosorbent assay (ELISA) kit was used to determine Interleukin-6 in study samples. Pearson correlation was used to find the correlation between genotoxicity and IL-6.

Results: The mean IL- 6 and micronuclei frequency was $49.48 \pm 19.69 \mathrm{ng} / \mathrm{L}$ and $6.77 \pm 0.73$, respectively. Weak positive association was found between micronuclei frequency and IL-6 in smoke exposed rats $(r=0.266, N=70, p=0.026)$.

Conclusion: Genotoxicity and inflammation are associated in smokers. The present study concluded that smoke exposure elicited a proinflammatory profile, which might have promoted DNA damage in smokers.
\end{abstract}

Key Words: Cigarette smoking, IL-6, DNA damage, Rats.

\section{INTRODUCTION}

Cigarette smoking is the chief cause of avoidable morbidity and mortality. Cigarette smoke contains considerable adverse chemicals. These biohazards contribute to inflammation, oxidative stress and DNA damage. 1

Cigarette smoking is coupled to various health issues, including cancers, pulmonary and cardiovascular disorders; ${ }^{2}$ therefore, its toxicity is required to be evaluated. Raised inflammation and genotoxicity in smokers may be responsible for its destructive health impacts. ${ }^{3}$

Genotoxicity happens frequently, but DNA repair pathways in the cell generally repair it. In case of failure of DNA repair pathways, cells experience cell death or accumulate mutations in somatic cells, which lead to cancer development. ${ }^{4}$ Genotoxicity is produced by environmental exposure to genotoxins and lifestyle factors like alcohol, smoking, drugs and stress. Genotoxicity can lead to multiple diseases, such as neurodegenerative disorders, cancers, immune deficiencies, infertility and even aging. ${ }^{5}$ Genotoxicity is

1 Department of Biochemistry, Foundation University Medical College, Islamabad, Pakistan

2 Department of Biochemistry, Army Medical College, Rawalpindi, Pakistan

Correspondence: Dr. Aneela Jamil, Department of Biochemistry, Foundation University Medical College, Islamabad, Pakistan E-mail: aneela_55@yahoo.com

Received: February 12, 2018; Accepted: July 12, 2018 thought to be one of the mechanisms by which cigarette smoke initiates disease. 6

Micronucleus assay has been found to be an excellent tool to serve as a genotoxicological biomarker. Micronuclei (MN) are tiny fragments that appear in the cell cytosol during cell division as a result of chromosomal damage. ${ }^{7}$

Interleukine-6 (IL-6) is a multifunctional cytokine involved both in the beneficial acute inflammatory response and in the detrimental chronic low-grade systemic inflammation. ${ }^{8}$ IL- 6 has two different pathways for its induction of intracellular signaling: classic signaling and trans-signaling. ${ }^{9}$ In the classic pathway, IL- 6 binds the membrane-bound IL- 6 receptor, located on the surface of hepatocytes and some leukocytes, and activates the IL-6 classic signaling transduction cascade with the homodimerization of the membrane-bound $\beta$-receptor glycoprotein 130.10 In the trans-signaling axis, circulating IL-6 forms a heterodimer with the soluble form of IL-6 receptor, that could transduce a proinflammatory cascade in virtually any cell types through direct binding with membrane-bound gp130.11 Classic signaling is mainly responsible for the beneficial regenerative and antibacterial effects of IL-6,12 while the trans-signaling seems to account for the majority of the deleterious effect of IL-6.13

Cigarette smoke can provoke inflammation through stimulation of inflammatory cells which produce proinflammatory cytokines. Chronic inflammation is broadly recognized to generate cancer development through genotoxicity. 14 However, little is known about the correlation between the IL-6 and DNA damage in smokers. 
This study, therefore, aimed to investigate the relationship between inflammation and DNA damage in smokers.

\section{METHODOLOGY}

It was an experimental study carried out at Army Medical College, Rawalpindi and Armed Forces Institute of Pathology (AFIP), Rawalpindi in 2016, after approval by Ethical Committee of Army Medical College. Seventy healthy Sprague Dawley rats were procured in the animal house of $\mathrm{NIH}$, Islamabad. Healthy Sprague Dawley rats weighing $220 \pm 30$ grams and age between 6-8 weeks were included in the study. Diseased rats at the time of study were excluded from the study.

The animals were placed in smoke chambers and supplied with pelleted food and water ad libitum. Cigarette smoke was given to rats for four hours per day for five days a week for 12 weeks.

At the end of 12 weeks, 6-7 ml blood was collected from each rat. Three $\mathrm{ml}$ was poured into the vacuum tubes containing clot activator. It was centrifuged and serum obtained was stored at $-80^{\circ} \mathrm{C}$. ELISA kit was used to measure IL-6 in the study samples.

Three $\mathrm{ml}$ blood was taken into the lithium heparinized tubes for estimation of micronucleus frequency by cytokinesis block micronucleus (CBMN) assay to assess genotoxicity. Lymphocyte cultures were performed. Frequency of micronuclei, was quantified in 1000 lymphocyte nuclei from each sample. The micronuclei were of different sizes, and before being accepted as micronuclei they were compared with the main nucleus in terms of size, structure, color, and number.

SPSS version 17 was used to analyse the data. Mean and standard deviation (SD) was calculated for IL-6 and MN frequency. Correlation between IL-6 and MN frequency was determined by Pearson correlation test. A $p$-value $<0.05$ was considered statistically significant.

\section{RESULTS}

The correlation between mean of Interleukin-6 and micronuclei frequency in smoke exposed rats. The mean IL-6 and micronuclei frequency was $49.48 \pm 19.69 \mathrm{ng} / \mathrm{L}$ and $6.77 \pm 0.73$, respectively. 15 Statistically significant weak positive correlation was found between IL-6 and micronuclei frequency $(r=0.266, \mathrm{~N}=70, \mathrm{p}=0.026)$.

\section{DISCUSSION}

Cigarette smoking and tobacco chewing are common modes of consuming tobacco.16 Cigarette smoke, a major public hazard, is a detrimental blend of numerous compounds which may induce carcinogenesis by their mutagenic and genotoxic effects. ${ }^{17}$ Cigarette smoke also contains many oxidants and free radicals that induce oxidative damage. ${ }^{18}$ Oxidative stress induced by tobacco smoking is one of the main causes of DNA damage and is known to be involved in the development of several cancers. ${ }^{19}$

Cigarette smoke causes oxidative damage in DNA, either directly or through generation of reactive oxygen species as evidenced by human and animal studies. ${ }^{20}$ Tobacco exposure is the leading cause of cancers involving the oral cavity, conductive airways, and the lung. 21

Wolz et al. carried out his study to explore the genotoxic effects of sidestream cigarette smoke at different concentrations using the alkaline comet assay. Human bronchial epithelial cells were exposed to sidestream smoke or fresh air for 1 hour. Results showed that sidestream cigarette smoke exposure causes significant DNA strand breaks. 22

IL-6 is a cytokine with a multifactorial function and induces both pro- and anti-inflammatory responses. ${ }^{23}$ Cigarette smoke exposure induces inflammation in both humans and mice. 24

Conflicting results were reported by Koczulla et al. He conducted a study to show the effect of smoking on inflammatory mediator, IL-8. Twenty-nine smokers and 19 non-smokers were enrolled in the study. IL-8 levels were determined by ELISA in each participant. Results showed no significant change in the level of IL-8 between the groups. ${ }^{25}$

In cigarette smokers, $p 53$ gene is commonly mutated. This gene is a tumor suppressive gene, so mutations affecting p53 gene lead to unchecked cellular growth and tumor formation. Many studies have illustrated that cigarette smoke induces DNA-strand breaks in mammalian cells, and sister chromatid exchanges are shown in bone marrow and lung cells exposed to cigarette smoke indicating its genotoxic effect. Moreover, increased trend of mutations, translocations and DNA strand breaks have been found in newborns of smoking mothers in humans. Genotoxicity induced by cigarette smoke is employed not only through direct damage to DNA but also through indirect mechanisms; for example, chronic inflammation and production of reactive oxygen species. ${ }^{26}$

The results of this study showed that plasma proinflammatory cytokine, IL-6, was elevated in the smoke exposed rats. Micronuclei were also enhanced in plasma of exposed rats, indicative of DNA damage. Inflammation is associated with increased DNA damage; whereas, the link between inflammation and genotoxicity is still obscure in smokers. To the best of authors' knowledge, no study in Pakistan has yet determined the relationship between IL- 6 and micronuclei frequency in smokers. This study determined correlation between IL-6 and micronuclei frequency and results showed significant positive association, thus linking inflammation and genotoxicity in smokers. 


\section{CONCLUSION}

The present study concluded that smoke exposure elicited a proinflammatory profile which might have promoted DNA damage in smokers. However, further studies are needed to probe into the details of mechanisms associated with these findings.

\section{REFERENCES}

1. Qiu F, Fan P, Nie GD, Liu H, Liang CL, Yu W, et al. Effects of cigarette smoking on transplant survival: Extending or shortening It? Front Immunol 2017; 8:127.

2. Kim HR, Lee JE, Jeong MH, Choi SJ, Lee K, Chung KH. Comparative evaluation of the mutagenicity and genotoxicity of smoke condensate derived from Korean cigarettes. Environ Health Toxicol 2015; 30:e2015014.

3. Khabour OF, Alzoubi KH, Bani-Ahmad M, Dodin A, Eissenberg T, Shihadeh A. Acute exposure to waterpipe tobacco smoke induces changes in the oxidative and inflammatory markers in mouse lung. Inhal Toxicol 2012; 24:667-75.

4. Yasuda MT, Sakakibara H, Shimoi K. Estrogen- and stressinduced DNA damage in breast cancer and chemoprevention with dietary flavonoid. Genes Environ 2017; 39:10.

5. Saez GT. DNA Damage and repair in degenerative diseases 2016. Int J Mol Sci 2017; 18:e166.

6. Dalrymple A, Ordonez P, Thorne D, Dillon D, Meredith C. An improved method for the isolation of rat alveolar type II lung cells: Use in the Comet assay to determine DNA damage induced by cigarette smoke. Regul Toxicol Pharmacol 2015; 72:141-9.

7. Gemitha G, Sudha S. Assessment of genotoxicity among rubber industry workers occupationally exposed to toxic agents using micronucleus assay. Iran J Cancer Prev 2013; 6:73-7.

8. Larsen JV, Petersen CM. SorLA in interleukin- 6 signaling and turnover. Mol Cell Biol 2017; 37:e641.

9. Petkovic F, Castellano B. The role of interleukin-6 in central nervous system demyelination. Neural Regen Res 2016; 11: 1922-3.

10. Scheller J, Garbers C, Rose-John S. Interleukin-6: from basic biology to selective blockade of pro-inflammatory activities. Semin Immunol 2014; 26:2-12.

11. Morieri ML, Passaro A, Zuliani G. Interleukin-6 "Trans-signaling" and ischemic vascular disease: The important role of soluble gp130. Mediators Inflamm. 2017; 2017:1396398.

12. Luig M, Kluger MA, Goerke B, Meyer M, Nosko A, Yan I, et al. Inflammation-induced IL-6 functions as a natural brake on macrophages and limits GN. J Am Soc Nephrol 2015; 26: 1597-607.
13. Garbers C, Aparicio-Siegmund S, Rose-John S. The IL-6/gp130/ STAT3 signaling axis: Recent advances towards specific inhibition. Curr Opin Immunol 2015; 34:75-82.

14. Aoshiba K, Tsuji T, Yamaguchi K, Itoh M, Nakamura $H$. The danger signal plus DNA damage two-hit hypothesis for chronic inflammation in COPD. Eur Respir J 2013; 42:1689-95.

15. Jamil A, Rashid A, Naveed AK. Effect of smoking on interleukin-6 in Sprague Dawley rats. Pak Armed Forces Med J 2018; 68:658-63.

16. Kumar SB, Chawla B, Bisht S, Yadav RK, Dada R. Tobacco use increases oxidative DNA damage in sperm-possible etiology of childhood cancer. Asian Pac J Cancer Prev 2015; 16:6967-72.

17. The health consequences of smoking- 50 years of progress: A report of the surgeon general. Atlanta (GA) 2014.

18. Lymperaki E, Makedou K, Iliadis S, Vagdatli E. Effects of acute cigarette smoking on total blood count and markers of oxidative stress in active and passive smokers. Hippokratia 2015; 19:293-7.

19. Cao C, Lai T, Li M, Zhou H, Lv D, Deng Z, et al. Smokingpromoted oxidative DNA damage response is highly correlated to lung carcinogenesis. Oncotarget 2016; 7:18919-26.

20. Pirini F, Guida E, Lawson F, Mancinelli A, Guerrero-Preston R. Nuclear and mitochondrial DNA alterations in newborns with prenatal exposure to cigarette smoke. Int J Environ Res Public Health 2015; 12:1135-55.

21. Gibbons DL, Byers LA, Kurie JM. Smoking, p53 mutation, and lung cancer. Mol Cancer Res. 2014; 12:3-13.

22. Wolz L, Krause G, Scherer G, Aufderheide M, Mohr U. In vitro genotoxicity assay of sidestream smoke using a human bronchial epithelial cell line. Food Chem Toxicol 2002; 40: 845-50.

23. Wolf J, Rose-John S, Garbers C. Interleukin- 6 and its receptors: a highly regulated and dynamic system. Cytokine. 2014; 70 : 11-20.

24. Pouwels SD, Heijink IH, van Oosterhout AJ, Nawijn MC. A specific DAMP profile identifies susceptibility to smokeinduced airway inflammation. Eur Respir J 2014; 43:1183-6.

25. Koczulla AR, Noeske S, Herr C, Jörres RA, Römmelt $H$, Vogelmeier $\mathrm{C}$, et al. Acute and chronic effects of smoking on inflammation markers in exhaled breath condensate in current smokers. Respiration 2010; 79:61-7.

26. Momi N, Kaur S, Ponnusamy MP, Kumar S, Wittel UA, Batra SK. Interplay between smoking-induced genotoxicity and altered signaling in pancreatic carcinogenesis. Carcinogenesis 2012; 33:1617-28. 